\title{
VISÕES DE FILOSOFIA: INFÂNCIA
}

VIEWS OF PHILOSOPHY: INFANCY

Walter Omar Kohan

Universidade do Estado do Rio de Janeiro

Rio de Janeiro

Brasil

A palavra filosófica não captura o desejo; pelo contrário, seu dono é essa velha criança nua.

J.-F. LYOTARD, 2012

\section{Resumo}

Este trabalho é um ensaio sobre as relaçóes entre infância e filosofia. Sócrates e J.-F. Lyotard são as duas figuras principais que o inspiram. O primeiro, como um infante da filosofia, alguém que deu à filosofia uma infância como modo de vida, não apenas cronológica. O segundo, a partir de seu conceito de infantia, como forma do inumano que acompanha o ser humano na sua vida toda. A partir dessas inspiraçóes, este ensaio busca tecer diversas relaçóes da infância e da filosofia com conceitos como tempo, escola, política, escrita e arte.

Palavras-chave: Sócrates; J.-F. Lyotard; infância; filosofia; política.

\section{Abstract}

This essay draws some lines on the relationship between infancy and philosophy. Socrates and Lyotard are the two mains inspiring figures. The former, as an infant of philosophy, who gave an infancy, not only chronological, to philosophy, as way of life. The later, with his concept of infantia, as a form of the inhuman that accompanies every human being in his whole life. From these two inspirations, this essay draws different relationships between childhood and philosophy with concepts like time, school, politics and arts.

Keywords: Socrates, J.-F. Lyotard; infancy; philosophy; politics.

\section{Resumen}

Este trabajo es un ensayo sobre las relaciones entre infancia y filosofía. Sócrates y J.F. Lyotard son las dos figuras principales que lo inspiran. El primero, como un infante de la filosofía, alguien que le dio a la filosofía una infancia como modo de vida no solo cronológico. El segundo, a partir del concepto de infantia, como forma de lo inhumano que acompaña al ser humano en toda su vida. A partir de esas inspiraciones este ensayo busca establecer diversas relaciones de la infancia y la filosofía con conceptos como tiempo, escuela, política, escritura y arte.

Palabras clave: Sócrates, J.F-Lyotard, infancia, filosofía, política.

Seduzem-me muito as visóes, em plural, da infância, os relatos vindos especialmente da memória e da imaginação, com tudo o que podem querer 
significar uma e outra. A temática me toca pessoal e profissionalmente: vivo de visóes de infância, de relatos da memória e da imaginação. Vivo de imaginar uma infância ainda por vir, de rememorar uma memória infantil do futuro. A infância, devemos dizê-lo claramente desde o início, é um mistério, um enigma, uma pergunta. Não me refiro, claro está, apenas a uma etapa cronológica da vida humana, mas antes que qualquer outra coisa, a essa condição que nos habita - às vezes de forma mais perceptível, às vezes quase imperceptível - desde que habitamos o mundo. Essa condição que, também devemos dizê-lo desde o começo, não nos abandona, mesmo na forma do silêncio ou de uma presença imperceptível, até que abandonamos o mundo.

Em algum momento sublime do universo, comecei a me aproximar da infância através da filosofia. Primeiro, pela mão de filósofos - como Matthew Lipman - que pensaram fazer da prática da filosofia uma estratégia de formação democrática das crianças, da infância cronológica. Aos poucos, a infância foi tomando voos próprios, habitando tempos distintos e me levando a outros caminhos pela própria filosofia que também voava junto. A partir desse encontro, a relação que se descortinou entre uma e outra foi extremamente complexa, intensa e rica. Como diz um dos filósofos contemporâneos que tem se mostrado mais atento a certa infância, o francês J.F. Lyotard, a filosofia e a infância andam de mãos dadas, pois aquela não é outra coisa senão a "infância do pensamento", ou seja, essa infinita potência de recomeço no pensamento que a pergunta instaura e mostra que, em última instância, quando pensamos, estamos sempre no começo. Para dizê-lo com outras palavras: pensar de verdade, pensar-se a si mesmo, fazer da filosofia um exercício de se colocar a si mesmo em questão exige, a cada momento, ir até a mais recôndita infância do pensamento, começar a pensar tudo de novo como se nunca tivéssemos pensado, como se, a cada vez, estivéssemos pensando pela primeira vez. Assim, a infância é quase uma condição da filosofia.

Podemos perceber essa relação entre filosofia e infância pelo lado dos possíveis: a filosofia e o filosofar são também escuta atenta dos possíveis no pensamento, e a infância é, justamente, pelo menos num sentido, o reino das possibilidades e da ausência de determinação. Quando se entra na filosofia, lê-se sempre no seu frontispício: "Tudo pode ser de outra maneira". Se não for, não há o que pensar. Por fim, e ainda mais perto desse exercício, a infância é a marca da própria escrita em filosofia, que se antecipa ao escrever, que se escreve antes de saber e para saber. Uma escrita filosófica que, segundo Lyotard, é como uma criança: "prematura e inconsistente" (LYOTARD, 2005). Desse modo, ainda que as pretensóes e apostas de alguns filósofos neguem ou desprezem essa dimensão infantil, a filosofia nunca abandona tal condiçáo, exceto para correr o risco de se abandonar, infrutuosamente, ela própria. 
Sócrates, sempre Sócrates. Infante, filósofo, o primeiro - mesmo que existam os "pré-socráticos" -, diz claramente, no início de sua defesa, que é a defesa da filosofia perante a política que a acusa: "os acusadores falaram tão bem que quase me esqueci de mim mesmo, de quem eu sou...”. Sócrates, ninguém menos, fundando a filosofia entre a vida e a morte, expressa os riscos de se esquecer de quem é; da própria filosofia com a qual se identifica como estratégia de defesa... E, então, fará sua apologia falando a língua da sua infância. Perante o risco de morte, a filosofia lembra e chama à infância.

Sócrates é, por várias razôes, um caminho interessante para entrar na filosofia como infância do pensamento. É o primeiro porque, como disse A. Heller (1978), sua figura é quase uma condiçáo para filosofar em qualquer tempo: pela forma em que situou a filosofia entre a vida e a morte; pelos seus infinitos rostos às vezes contraditórios, impossíveis, exagerados e porque parece que, se estamos dentro da filosofia, não podemos deixar de vestir pelo menos algumas de suas infinitas máscaras... Máscaras essas que retratam seu caráter infantil: estrangeiro, intratável, perguntador, incômodo, sem lugar, o mais sem lugar (atopóstatos) de todos, talvez o mais infante em Atenas, a única cidade onde podia viver.

Outro francês - J. Derrida (1997) - apresenta, em um diálogo sobre a hospitalidade, essa lembrança de Sócrates no início da sua defesa, esforçandose em marcar o seu não-lugar estrangeiro ante os discursos imperantes nos tribunais da pólis. Pela primeira vez diante dos tribunais, aos 70 anos, pede permissão para falar a língua infantil em que foi educado. Sócrates, correndo risco de morrer, chama a língua da sua infância, aquela na qual foi criado e com a qual conversa com seus interlocutores nas ruas da cidade, identificandose com a filosofia. Improvisando, sem saber, perguntando-se, como se fosse um estrangeiro, não fala a língua adulta da cidade. Afirma, infantilmente, que a acusação contra ele é uma acusação contra os que filosofam. A infância dá voz a uma vida que se aferra à filosofia perante a iminência da morte.

A maneira como Sócrates se defende mostra outras máscaras do seu rosto infantil. As acusaçôes são duas: introduzir novos deuses e corromper os jovens. O filósofo ateniense se diverte com a primeira delas: os acusadores dizem que ele é irreligioso, e Apolo, o principal deus de Atenas, afirma que na cidade não há ninguém mais sábio do que Sócrates. Como se isso não bastasse, Sócrates zomba dos juízes. A filosofia se mostra ignorante e ele se pergunta como o oráculo pode tê-lo apontado como o homem mais sábio de Atenas. Não compreende, mas, como uma criança, sai em busca de possibilidades. Qual o sentido de o oráculo afirmar que não há ninguém mais sábio 
em uma cidade repleta de homens reconhecidos pela sua sapiência? Nada parece impossível para Sócrates, tampouco para a filosofia ou para a infância.

O que pode querer dizer o oráculo quando afirma que não há ninguém mais sábio do que Sócrates? O que parece impossível, primeiro se torna possível, depois necessário. Sócrates sai em busca da verdade, perguntando. Encontra um sentido no que parecia impossível: a ignorância e a sabedoria não são contrárias. No mundo adulto dos sábios, a ignorância é um vazio, uma falta, um defeito (ignorantia), e a sabedoria o seu contrário, uma presença, uma plenitude, uma virtude. Os que se apresentam como sábios se apresentam cheios, mas de fato estáo vazios. No mundo infantil da filosofia, reside outra forma de vazio: a ignorância é um saber; o mais sábio é quem sabe que não sabe; quem sabe ignorar, sabe não saber, ignora o saber que não se sabe e sabe o saber que pode permitir criar saber.

Por isso, na infância do pensamento, a ignorância tem vários significados possíveis: ela é ausência de saber, mas também é o saber afirmativo que não aceita o que "todo mundo" considera saber; é não querer saber o que, nem como, todo mundo sabe. Então, no mundo filosófico da infância, o mais sábio não sabe. Não sabe o saber que não se sabe a si mesmo e não sabe outro saber que o saber de querer sempre saber. A ignorância deixou de ser ausência, carência e insuficiência para tornar-se potência e motor dos possíveis.

O gesto de Sócrates é infantilmente impressionante: nada é apenas o que parece ser; tudo pode ser de outra maneira, inclusive da contrária que é. A ignorância sabe, o saber ignora; o ignorante sabe, o sábio ignora. Assim, com Sócrates, a filosofia nasce como infância e não poderia ser de outra maneira. Nesse cenário, a infância da filosofia é comovedoramente contrastante: frágil e potente; aberta e provocadora; estrangeira e hostil.

O problema maior de Sócrates não é apenas o que ele sabe. É que ele quer que os outros também saibam seu saber. Eis o que deu lugar à segunda acusação, corromper os jovens. Os acusadores têm razáo: Sócrates quer compartilhar o que sabe. Mais uma mostra de infância. E, então, sai a conversar com outros. Se ele próprio é insuportável, contagiando seu saber torna-se infinitamente mais insuportável. Há que extirpar a filosofia da pólis, há que extirpar a infância do pensamento.

A maneira como Sócrates responde a essa acusação é mais uma lição infantil: "Corromper os jovens? Eu jamais fui mestre de ninguém" (egò dè didáskalos mèn oudenòs pópot' egenómen; PLATÃO, 2001: Apologia de Sócrates, 33a). Há muitas negações nessa afirmação: jamais, ninguém. Sócrates tem razão. Ele não faz o que fazem os didáskaloi: a) não recebe dinheiro de quem deseja escutá-lo nem discrimina seus eventuais interlocutores pela idade ou pelo dinheiro; b) não ensina conhecimento algum (méte hypeschómen medeni 
medèn pópote máthema méte edídoxa. PLATÃO, 2001: Apologia de Sócrates, $33 \mathrm{~b}$. Outra vez, muitas negaçóes marcadas pero advérbio grego me), o que é lógico, porque nada sabe; c) se alguém diz que apreendeu dele, em privado, algo diferente do que afirma diante de todos os outros, não diz a verdade, já que ele se comporta da mesma maneira - diz o mesmo - em particular e em público.

Sócrates tem razão, mas também não tem razão. É claro que ele não faz o que fazem os professores da época, mas é justamente disso que ele é acusado. Se ele ensinasse como ensinam todos os que dizem ensinar, náo haveria problema algum. O problema é que ele não ensina como tem que ensinar ou como a pólis manda ensinar. Ele funda também uma infância da educaçáo. Faz nascer outro professor, outra relação com quem aprende e outra possibilidade de ensinar. Outra vez, a infância infinitamente afirmativa de Sócrates.

Derrida também sugere outros lugares em que Sócrates se mostra como um estrangeiro na pólis: no Críton, por exemplo, perante as leis. Está tudo combinado para Sócrates fugir tranquilamente de madrugada. Seus amigos oferecem toda espécie de argumentos: morrer é desatender aos filhos, dar razão aos seus inimigos, dar vida aos que combatem a filosofia... Sócrates, como sempre, inverte as coisas: a vida está na sua morte, em uma forma de morrer, docilmente, infantilmente, com justiça e verdade. A morte está na vida dos que vivem uma vida sem se questionar. No Fedro, antecedendo justamente o tribunal da escrita (DERRIDA, 2000), Sócrates colocará as condiçôes para estar dentro da filosofia, entre elas, dispor de "tempo livre" (scholè), escola, tempo de verdade, que se possa perder, liberado das exigências dos que querem submeter à vivência do tempo, o que é produzido nele (ainda que pareça, não havia membros da Capes no tribunal).

A associação entre infância e filosofia aparece também no Górgias, onde reverte numa crítica da filosofia, de sua inutilidade ou de sua periculosidade. A infância é vista de forma dominante, nesse e em outros diálogos, como algo menor ou inconveniente, e a associação entre ela e a filosofia serve para mostrar as fraquezas de uma e de outra. Sócrates tem ali conversado com o próprio Górgias e Pólo e, de certo modo, ridicularizado a ambos em suas pretensões de saber o que é a retórica. Cálicles, seu último interlocutor, entra furioso em cena e faz uma crítica mordaz de Sócrates. Pede para ele parar de agir como uma criança e distanciar-se da filosofia para dedicar-se a questóes mais importantes (PLATÃO, 2002: Górgias, 484c). A filosofia - sustenta Cálicles - corrompe os homens quando estes permanecem muito tempo nela e acaba tornando-os inexperientes (ápeiron) e ridículos para o mais importante: a vida pública, política, na pólis (PLATÃO, 2002: Górgias, 484c-d). Assim, os filósofos se comportam como crianças. O filósofo é tão ridículo e infantil nos assuntos públicos - acrescenta - como os políticos nas conversas filosóficas. 
Cálicles oferece a seguinte comparação, que transcrevo pelo seu modo ilustrativo de associar filosofia e infância:

É belo o estudo da filosofia até onde for auxiliar da educação, não sendo essa atividade desdouro para os moços. Mas, prosseguir nesse estudo até idade avançada é coisa supinamente ridícula, Sócrates, reagindo eu à vista de quem assim procede como diante de quem se póe a balbuciar e brincar como criança. Quando vejo uma criança na idade de falar dessa maneira, balbuciando e brincando, alegro-me e acho encantador o espetáculo, digno de uma criatura livre e muito de acordo com aquela fase da existência; porém, se ouço uma criaturinha articular com correção as palavras, doem-me os ouvidos e acho por demais forçada essa maneira de falar, que se me afigura linguajar de escravos. Falar um adulto, pelo contrário, ou brincar como criança é procedimento ridículo, indigno de homens e merecedor de açoites. É precisamente isso que se dá comigo com relaçáo aos que se dedicam à filosofia. Alegra-me o espetáculo de um adolescente que se aplica no estudo dessa matéria; assenta-lhe bem semelhante ocupação, muito própria de um homem livre, como considero inferior e incapaz de realizar alguma açáo bela e generosa quem nessa idade descura da filosofia. Mas, quando vejo um velho cultivá-la a destempo, sem renunciar a tal ocupação, um homem nessas condiçôes, Sócrates, para mim é merecedor de açoites. Como disse há pouco, quem assim procede, por mais bem-dotado que seja, deixa de ser homem; foge do coração da cidade e das assembleias, onde, exclusivamente, no dizer do poeta, os homens se distinguem, para meter-se num canto o resto da vida, a cochichar com três ou quatro moços, sem jamais proferir um discurso livre, grande ou generoso. (PLATÃO, 2002: Górgias, 485a-d.)

Cálicles declara que é bonito dedicar-se à filosofia na medida em que serve à educação (paideia). A raiz dessa palavra está emparentada com a palavra país, que significa "criança”. Cálicles não aprecia as crianças, nem a educação, nem a filosofia. Todas elas fazem parte de um mundo inferior, anterior ao mundo real da política. A filosofia pode acompanhar a vida humana durante a fase do jogo (paizon), justamente porque é o momento de perder tempo, do tempo sem importância. Mas, aquele que se dedica à filosofia na vida adulta torna-se um homem desprezível (um anti-homem, an-androi), principalmente porque ele não ocupa um lugar público (ágora) no centro da cidade, lugares da realização da cidadania. Para Cálicles, o filósofo, como o infante, não é um cidadão.

Cálicles tem muita razão. À maneira socrática, sob formas infantis e estrangeiras de expressar-se em uma comunidade, a filosofia é completamente atópica: ela busca desconhecer todas as coisas, questioná-las, desaprender o que sabemos, afirmar o valor do não saber e do buscar responder, com todas as suas forças, questóes que não podem ser respondidas. Essa prática da filosofia é insuportável para legislar um estado de coisas. Ela não é nem deixa ser ao conhecimento, é apenas uma relação perturbadora com os conheci- 
mentos consagrados. Do mesmo modo, ela náo ensina - nenhum saber tem a ensinar -, mas provoca aprendizagens, a respeito de si mesmo e das formas de vida compartilhadas. É infantil demais a filosofia socrática, insuportável para qualquer especialista em legislar a vida.

Mudando algumas palavras, a valoração da infância e da filosofia afirmada sem reparos por Cálicles tem muitos adeptos em nosso tempo. Há algo menor, muito infantil (no sentido mais banal da palavra) nesse andar questionando as coisas sem fim. Além disso, ela não só é inútil como também perigosa, pelos desvios, incertezas, estrangeiridades, pela sua incapacidade de formar as crianças para o mundo "real". Por isso, ela deve ser expurgada da pólis. Em todos os tempos, há pretensos juízes do pensamento. Por isso, a língua infantil de Sócrates não é escutada nos tribunais e a sua vida deve ser exemplarmente punida.

Este é o paradoxo de Sócrates, do phármakon (droga, remédio, veneno) filosófico que ele inventa. Sócrates - a filosofia, a infância - não tem lugar na pólis, não sabe falar a sua língua; essa língua é o que a pólis mais precisa e, ao mesmo tempo, o que a pólis náo pode suportar... ela diz infantilmente o que a pólis não pode nem quer ouvir: a questiona, a interpela, a faz lembrar do que ela pretende ter deixado atrás e não quer recordar.

Sócrates, como vemos, afirma uma figura infantil no pensamento. É um filósofo infantil, um amigo da infância. Ele inventa um modo infantil de habitar a filosofia como forma de vida, como estilo de viver perguntando, questionando, incomodando, falando uma língua estranha, estrangeira, inabitável... Vive a filosofia e vive a infância... Outro francês, M. Foucault (2009), mostrou como, a partir do mesmo Sócrates, já nos diálogos de Platão, duas linhas da filosofia nascem: ela pode ser modo de viver - como Sócrates o afirma e exemplifica, além da Apologia, em diálogos como o Láques - ou exercício cognitivo - como no Alcibiades I, onde, enquanto conhecimento de si, é uma condição para o cuidado dos outros. Ao longo da história, cada vez mais se foi intensificando a filosofia como atividade intelectual e, cada vez mais, reduzindo-se como modo de vida...

Assim, a maior parte dos que hoje chamamos de filósofos tem muito mais a ver com essa tradiçáa dominante de conceber a filosofia como atividade cognitiva, intelectual. Quando os lemos, entramos em contato com o resultado dessa atividade intelectual. Alguns deles têm dado, nessa atividade, particular atenção à infância. Para seguir com os franceses, importame dar testemunho de J.-F. Lyotard. Nos seus escritos, a infância aparece de formas variadas. Por exemplo, é interessante notar como um dos seus livros mais emblemáticos ( $O$ pós-moderno) está constituído por cartas escritas para crianças. $\mathrm{O}$ autor termina esse livro com um curioso e instigante "Memorial 
sobre o curso de filosofia”, em que descreve a filosofia como uma autodidática, uma prática de recomeçar a cada vez no pensamento. Eis as últimas três linhas do livro:

O pensamento talvez tenha mais infância disponível entre os de 35 anos que entre os de 18, e fora do curso de estudos mais do que dentro. Nova tarefa para o pensamento didático: buscar sua infância em qualquer parte, inclusive fora da infância. (LYOTARD, 2005)

Há dois sentidos aqui afirmados para a infância: que ela possa estar fora da infância significa que, como começo, interrupçáa, estrangeiridade do pensamento, pode estar fora da idade cronológica que costumamos demarcar como infância e, também, que somos habitados pela infância para muito além de uma fase cronológica da vida.

Em outros trabalhos, Lyotard se ocupou de pensar mais detalhadamente essa infância não cronológica que nos ocupa. ${ }^{1}$ Entre os muitos sentidos que se têm dado à infância, apresento um: a infantia como a diferença entre o que pode e náo pode ser dito, o indizível, algo perdido que habita imperceptivelmente o dizível como sua sombra, seu lembrete, um náo dito que obra como uma condiçấo para que se possa dizer algo com sentido.

Nesse sentido, a infantia como condição latente que está por trás de cada palavra pronunciada por qualquer ser humano é uma forma do inumano. Mas, o que é o inumano? Lyotard por sua vez, distingue duas de suas formas (LYOTARD, 1989): o inumano do sistema, chamado de "desenvolvimento", "competitividade", "democracia representativa", "mercado", "mundo livre", e o inumano que cada alma humana carrega pelo fato de ter nascido de uma indeterminação forçada a se abandonar a si própria, a se determinar sem poder fazer nada para evitá-lo. A segunda forma do inumano é essa passagem do não ser ao ser da qual todos nascemos e ninguém escolheu. Fomos forçados a nascer, nenhum ser humano foi perguntado se queria vir ao mundo.

Essas duas formas do inumano são encontradas, opostas. Vejamos, por exemplo, em relação ao tempo. A primeira impóe a necessidade de correr atrás do tempo, de fazer um bom e produtivo uso dele, ser eficiente, eficaz na forma de percorrer essa linha extensiva, sucessiva, consecutiva, irreversível de movimentos cronológicos que constituem sua imagem preferida do tempo. A segunda não corre atrás do tempo, deixa o tempo se perder em percursos não lineares, mas polimorfos, intensivos, repetitivos, de forma complexa ou, ainda, anda distraída em busca do tempo perdido, especialmente aquele tempo remoto da indeterminação, abandonada num movimento em que o

\footnotetext{
${ }^{1}$ Para um estudo mais detalhado da concepção de infância em Lyotard, sugiro: SMEYERS; MASSCHELEIN (2012); FRY (2014) e, particularmente, LOCKE (2012), que desdobra, nos três sentidos que aqui apresentamos, a forma complexa em que Lyotard trabalha o conceito de infância.
} 
passado nem sempre antecede o presente e o futuro pode não sucedê-lo. É o tempo circular, de eterno retorno, dos ciclos, como o tempo dos aimarás, de um passado que está na nossa frente porque se pode ver e do futuro que está atrás porque é desconhecido.

No campo da economia, abre-se um caminho para a política. Se a primeira forma do inumano busca impor o capital em todas as suas variantes como uma única ideia triunfante e hegemônica, com a lógica consequência de que não haveria alternativas possíveis ao sistema e que nenhuma outra ideia seria viável para além dela própria, Lyotard considera que a política só pode ser a resistência a essa forma capitalista de inumano, em nome da memória daquela outra forma de inumano esquecida, aquela de uma alma que constantemente lembra a dívida com o inumano do qual nasceu. Em suas palavras:

(...) que mais resta de "político" que não seja a resistência a este inumano? E que mais resta, para opor resistência, que a dívida que toda a alma contraiu com a indeterminação miserável da sua origem, da qual não cessa de nascer? Ou seja, com o outro inumano? Esta a dívida que temos para com a infância e que não é saldada. Mas basta não esquecer para resistir e, talvez, para não ser injusto. Esta é a tarefa da escrita, do pensamento, da literatura, das artes, aventurar-se a prestar testemunho. (LYOTARD, 1989)

Basta não esquecer a dívida com a infância para não ser injusto. Basta não esquecer a dívida com a infância para não ser injusto? Não o sabemos. Mas em tempos em que afloram os discursos de formação da infância, ainda em nome da filosofia, talvez uma tarefa política interessante para o pensamento seja lembrar que não existem motivos nem modos de acabar com a infância. Ela nos constitui como forma de sinal de nossa condição indeterminada. Lembrá-la, na escrita, na arte, na educação, constitui uma força, um estilo, uma forma política de testemunho.

Eis uma tarefa da escrita. Ao mesmo tempo impossível e necessária. Impossível porque escrevemos para dar forma a uma infância que em nenhum caso se deixa escrever. Necessária como tarefa política de lembrar e afirmar aquela forma do inumano que é silenciada, negada pela outra forma do inumano dominante. A escrita é necessária e impossível como a filosofia, como a infância, uma espécie de sobrevivente, uma entidade que deveria estar morta, mas ainda está viva (LYOTARD, 1997: 63).

Como sobrevivente, a infância é também uma esperança: "o acontecimento de uma alteração radical possível no fluxo que empurra as coisas a repetir o mesmo" (LYOTARD, 1997: 62). A infância nomeia algo que "já é", mas sem ser ainda "algo", uma espécie de espanto que introduz no mundo do humano uma forma do inumano que ainda não pode ser identificada; 
a infância é o nome de um milagre, o da interrupção do ser das coisas pela entrada de seu outro, do outro do ser.

Dívida, esperança, milagre, pode a infância encontrar seu lugar na escola? Parece difícil na escola do inumano, do currículo, das avaliações, das séries que progridem para preparar a infância para um tempo melhor, para que as crianças possam abandonar aprazivelmente a infância e habitar o mundo dos assuntos que contam e importam. Contudo, essa escola é também habitada por outra: a escola como scholé, a escola do tempo livre, liberado, da lembrança do outro esquecido, de um tempo aiônico, sem sequência de passado, presente e futuro. Nos tempos atuais, a escola como scholé parece tão necessária quanto impossível. Quem sabe essa lembrança do tempo perdido possa se configurar como uma força política de habitar a escola, ainda ou sobretudo, em nome da filosofia, da infância ou de sua reunião?

Finalmente, a infância é uma forma de tempo sensível: "A capacidade de sentir prazer e dor, afetividade, aisthesis, é independente de sua possível articulaçâa... este tempo antes do logos é chamado infantia" (LYOTARD, 2006: 109). Um tempo antes do logos, um tempo afetivo, sentido. Outra vez, a infância chama à filosofia: philo-sophía, phílos: afeto, paixão, amizade. A filosofia é, como a infância, um tempo sensível, antes do logos, antes do tempo. Antes náo significa necessariamente aqui, anterior na linha cronológica, significa um tempo primeiro, inicial, inaugural, uma condição.

Assim, a privação da infância significa, como afirma Locke (2012), a negação de todos os modos de expressão, sentido e articulação, quase que um retorno do humano ao inumano. Não há vida só na infância. Mas tampouco há vida sem infância. Outra vez, o paradoxo, o enigma, o impossível. Nessa exigência incontornável da presença de uma ausência, se encontram, mais uma vez, infância e filosofia. Esses dois impossíveis, necessários para que existam vida e morte como formas de expressão e sentido, para que uma vida seja vivível para um ser humano. Eis a tarefa política da escrita, da arte, da educação, da filosofia: lembrarmo-nos de que somos infância e quase nada mais.

Revisão de Peter de Sá Ferreira

Referências bibliográficas

DERRIDA, Jacques. De l'hospitalité. Anne Dufourmantelle invite Jacques Derrida à répondre. Paris: Calmann-Lévy, 1997.

"La pharmacie de Platon". In: PLATON, Phèdre, Traduction L. Brisson. Paris, GF- Flammarion: 255-403, 2000. 
FOUCAULT, M. Le courage de la vérité. Le gouvernement de soi et des autres II. Cours au Collège de France, 1983-1984. Paris: Gallimard; Seuil, 2009. Ed. Port.: A coragem da verdade. Trad. Eduardo Brandão. São Paulo: WMF Martins Fontes, 2011.

FRY, Karin. Lyotard and the philosopher child. Childhood \& Philosophy, v. 10, n. 20, 2014: 233-246.

HELLER, Agnes. A filosofia radical. São Paulo: Brasiliense, 1978.

LIDDELL, Henry, SCOTT, Robert. A greek english lexicon. Oxford: Clarendon Press, 1966.

LOCKE, Kirsten. Lyotard's Infancy: A debt that persists. Postmodern Culture, v. 23, n. 1, set. 2012:

LYOTARD, Jean-François. O inumano: consideraçóes sobre o tempo. Lisboa: Estampa, 1989.

. Lecturas de infancia. Buenos Aires: EUDEBA, 1997.

. Le postmoderne expliqué aux enfants. Paris: Galilée, 2005.

. "The AffectPhrase." Trans. Keith Crome. In: CROME, Keith; WILLIAMS, James (eds.) The Lyotard reader and guide. Edimburgo: Edinburgh UP, 2006.

. Pourquoi philosopher? Paris: PUF, 2012.

PLATÃO. O Banquete / Apologia de Sócrates. Trad. Carlos Alberto Nunes. Belém: EDUFPA, 2001.

. Protágoras / Górgias / Fedão. Trad. Carlos Alberto Nunes. Belém: EDUFPA, 2002.

SMEYERS, Paul; MASSCHELEIN, Jan. L'enfance, education and the politics of meaning. In: DHILLON, Pradeep; STANDISH, Paul (ee.). Lyotard. Just Education. Londres: Routledge, 2012: 140-156.

Walter Omar Kohan é pós-doutor em filosofia pela Universidade de Paris 8. É professor titular da Universidade do Estado do Rio de Janeiro (UERJ), pesquisador do Conselho Nacional de Desenvolvimento Científico e Tecnológico (CNPq) do Brasil e da Fundação de Amparo à Pesquisa do Estado do Rio de Janeiro (FAPERJ). Ganhou o prêmio "Cientista do Nosso Estado" na área Educação em 2008. É autor de Sócrates, el enigma de enseñar (Buenos Aires: Biblos, 2009); Filosofía, la paradoja de aprender y enseñar. (Buenos Aires: Libros del Zorzal, 2008); Infância, estrangeiridade e ignorância (Belo Horizonte: Autêntica Editora, 2007); Infância: entre educação e filosofia. Belo Horizonte: Autêntica Editora, 2003). E-mail: wokohan@gmail.com.

Recebido em: 14/04/2015 